\title{
Empregabilidade do profissional formado nos cursos superiores de tecnologia do CEFET-PR: estudo de caso em médias e grandes empresas da região norte do Paraná ${ }^{1}$
}

\section{Resumo}

presente trabalho discute a necessidade das empresas da região Norte do Paraná, por profissionais formados nos Cursos Superiores de Tecnologia. Trata-se de uma pesquisa exploratória que, em função dos procedimentos técnicos adotados, pode ser caracterizada como um estudo de caso. método de pesquisa empregado foi o indutivo. Os resultados mostram que há por parte das empresas a necessidade por profissionais formados nos Cursos Superiores de Tecnologia, na maioria dos casos, ele atua dentro de sua área de formação, e sua convivência com outros profissionais formados nas áreas tecnológicas ocorre normalmente. Concluiu-se que o tecnólogo no ambiente produtivo é um profissional necessário e que colabora em várias frentes, principalmente em face às novas tendências tecnológicas, uma vez que o mesmo recebe conhecimento teórico e prático e pode contribuir eficaz- mente tanto com as empresas quanto com a sociedade.

Palavras-chave: Educação profissional. Tecnólogo. Mercado de trabalho.

\section{Abstract}

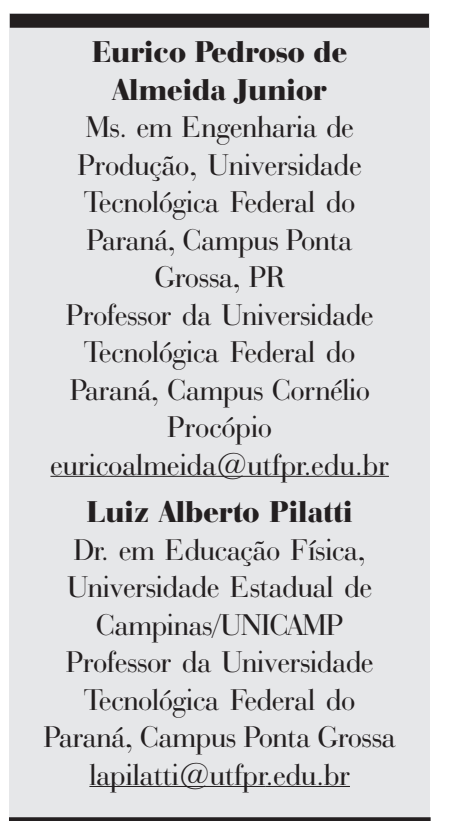

Empregability of the graduates in the

undergraduate courses of

technology: study of case in medium-sized and large companies in the northern region of the state Paraná

The present paper discusses the needs from the northern Paraná companies for professionals graduated on Technological

1 Este artigo é uma síntese da dissertação apresentada e aprovada no Programa de Mestrado em Engenharia de Produção da Universidade Tecnológica Federal do Paraná, Campus Ponta Grossa, no ano de 2005. 
College Courses. It is an exploratory research that due to its adopted technical procedures may be characterized as a case study. The research method used was the inductive one. The results show that there is the necessity by the companies of professionals graduated on Technological College Courses, in their majority, who usually act within their specific area and their intimacy to other professionals on technological areas happens naturally. The conclusion of the research introduces the technologist within the productive environment as a professional to require as well as to collaborate to several fronts, mainly facing to the new technological tendencies since he gets a theoretical and practical knowledge and can contribute both to companies and society.

Keywords: Professional education. Technologist. Labor market.

\section{Resumen}

\section{Empregabilidad del} profesional graduado en los cursos superiores de tecnología: estudio de caso en las medias y grandes empresas de la región norte del Paraná

Esa investigación discute la necesidad de las compañías del área Norte de Paraná por profesionales formados en las Universidades de Tecnología. Es una investigación exploratoria que, por los procedimientos técnicos adoptados, puede caracterizarse como un estudio de caso. El método de la investigación usado fue el inductivo. Los resultados confirman que hay por parte de las compañías la necesidad de profesionales formados en las Universidades de Tecnología; en la mayor parte de los casos ellos actúan dentro de su área de formación específica, y su convivencia con otros profesionales formados en las áreas tecnológicas ocurre normalmente. La conclusión de la investigación presenta el tecnólogo en el ambiente productivo como un profesional necesario a colaborar en varios frentes, principalmente si pensamos en las nuevas tendencias tecnológicas, una vez que él recibe el conocimiento teórico y práctico y puede contribuir eficazmente tanto con las compañías en cuanto a la sociedad. Palabras clave: Educación profesional. Tecnólogo. El mercado del trabajo.

\section{Introdução}

A Educação Profissional e Tecnológica é fundamental para um país em desenvolvimento como o Brasil. Com a edição da Lei no 9.394 (BRASIL, 1996), a nova Lei de Diretrizes Básicas - LDB, e do Decreto $n^{\circ}$ 2.208 (BRASIL, 1997), que regulamentou a educação profissional no âmbito da nova legislação, profundas mudanças foram introduzidas no cenário educacional.

Em se tratando de uma lei bastante flexível, o novo desenho apresentado tinha uma convergência única, a da manutenção do nível de ensino, com a adoção dos modelos concomitante ou pós-médio, em substituição ao técnico integrado. No entanto, um caminho distinto foi percorrido por uma única instituição, o Centro Federal de Educação Tecnológica do Paraná - CEFET-PR.

O CEFET-PR, no ano de 1998, cessou a matrícula de novos cursos técnicos integrados de $2^{\circ}$ grau, que deixaram de existir com a nova LDB, para a implantação dos 
Cursos Superiores de Tecnologia - CST. A opção, posteriormente, serviu de modelo para a maioria dos Centros Federais de Educação Tecnológica - CEFET's, do país.

Atualmente, as instituições de ensino colocam à disposição do mercado de trabalho, grande número de egressos formados nos CST. Segundo dados de 2004 do Instituto Nacional de Estudos e Pesquisas Educacionais INEP, o número de matrículas entre os anos de 1999 e 2003 teve um crescimento de 29\%, sendo que o número de concluintes neste mesmo período aumentou $18,7 \%$.

Com efeito, pode-se questionar: esse "novo" profissional atende às necessidades do setor produtivo? Assim, uma leitura do cenário descrito, para um melhor entendimento do modelo educacional adotado, num momento em que a educação profissional procura estabelecer seus limites dentro do quadro educacional do país, é necessária. Também é que necessário esclarecer a compreensão equivocada de que o CST é uma formação que pode ser completada em tempo menor que um bacharelado, o que tem levado a uma acelerada expansão de oferta que pode trazer sérias conseqüências à identidade do tecnólogo.

O objetivo geral desta pesquisa foi analisar junto às médias e grandes empresas, parceiras do CEFET-PR/Unidade de Cornélio Procópio, da Região Norte do Paraná, a necessidade de profissio- nais formados nos CST, e a ocupação deles nestas empresas.

Dentro dos objetivos específicos, esta pesquisa procurou verificar:

1. se existe um espaço para atuação desse profissional entre o do técnico e o do engenheiro;

2. se o tecnólogo é um profissional requerido pelas empresas pesquisadas;

3. se o profissional tecnólogo atua, nas empresas pesquisadas, de acordo com a formação por ele recebida.

\section{Educação profissional no Brasil}

A preocupação de preparar o aluno para exercer o papel de cidadão na sociedade sempre esteve voltada às classes mais privilegiadas, na qual os filhos dos ricos eram preparados para seguirem profissões extremamente necessárias à continuidade do desenvolvimento do país. Para os chamados "desprovidos da sorte" restava ou, simplesmente, bastava criar cursos capazes de ensinar-Ihes um oficio, exemplo disto eram as Escolas de Aprendizes e Artífices criadas em 1909. Kuenzer (1997) salienta que era bem demarcada a trajetória educacional daqueles que iriam desempenhar funções intelectuais ou instrumentais numa sociedade que delimitava a divisão social e técnica do trabalho.

Em 1942, com a edição da reforma Capanema ${ }^{2}$ houve uma primeira intenção

2 Em 1942, por iniciativa do Ministro Gustavo Capanema, são reformados alguns ramos do ensino. Estas Reformas receberam o nome de Leis Orgânicas do Ensino, e são compostas pelos seguintes Decretos-lei, durante o Estado Novo: O Decreto-lei n ${ }^{\circ}$ 4.048, de 22 de janeiro, cria o Serviço Nacional de Aprendizagem Industrial - SENAI. - O Decreto-lei n 4.073, de 30 de janeiro, regulamenta o ensino industrial. - $\bigcirc$ Decreto-lei $n^{\circ} 4.244$, de 9 de abril, regulamenta o ensino secundário. $O$ Decreto-lei $n^{\circ} 4.481$, de 16 de julho, dispõe sobre a obrigatoriedade dos estabelecimentos industriais empregarem um total de $8 \%$ correspondente ao número de operários e matriculá-los nas escolas do SENAI. O Decreto-lei n ${ }^{\circ} 4.436$, de 7 de novembro, amplia o âmbito do SENAl, atingindo também o setor de transportes, das comunicações e da pesca. - O Decreto-lei n ${ }^{\circ} 4.984$, de 21 de novembro, compele que as empresas oficiais com mais de cem empregados a manter, por conta própria, uma escola de aprendizagem destinada à formação profissional de seus aprendizes. Ainda no espírito da Reforma Capanema é baixado o Decreto-lei n ${ }^{\circ} 6.141$, de 28 de dezembro de 1943, regulamentando o ensino comercial (observação: o Serviço Nacional de Aprendizagem Comercial - SENAC só é criado em 1946, após, portanto o Período do Estado Novo) (HISTÓRIA da educação..., [1998?]). 
de articulação do ensino secundário com a educação profissional. Também naquele ano foi criado o Serviço Nacional de Aprendizagem Industrial - SENAl, e logo a seguir, em 1946, o Serviço Nacional de Aprendizagem Comercial - SENAC, forma encontrada pela iniciativa privada para atender às demandas de mão-de-obra qualificada para o setor produtivo.

E para atender a uma demanda específica do setor produtivo, o governo federal lançou uma listagem de 52 habilitações plenas (nível médio) e 78 habilitações parciais (nível auxiliar), conforme Parecer 45/72, com a maior parte voltada para o setor secundário, mostrando a concordância da proposta pedagógica e do modelo de desenvolvimento pretendido (KUENZER, 1997, p. 18).

Acompanhando este processo de mudança no ensino de $2^{\circ}$ grau, e também buscando atender às necessidades do setor produtivo, em nome do desenvolvimento econômico da nação, a educação superior lançou como experiências pioneiras à implantação dos CST, iniciada pelo Estado de São Paulo, em 1970, com dois cursos na Fundação Educacional de Bauru, com base nos Art. 18 e 23 da Lei n 5.540 (BRASIL, 1968).

Para Acioli (2004), a trajetória da educação profissional de nível tecnológico sofreu limitações, com o Decreto n 547 (BRASIL, 1969), que autorizou algumas escolas técnicas formarem técnicos de nível superior em uma nova modalidade de engenharia, a engenheria de produção.

Ainda sobre a edição da Lei $n^{\circ} 5.540$ (BRASIL, 1968), Peterossi (1980) argumenta que, para atender às necessidades do mercado de trabalho e criar uma nova modalidade educacional, foram criados os cursos profissionais de curta duração, incorporando-os à estrutura universitária e não como uma alternativa paralela.

Com essa nova abertura do governo para implantação de cursos superiores profissionalizantes e, apesar de existirem normas e condições mínimas para o funcionamento desses cursos, na maioria dos casos, essas recomendações não foram acatadas. Quando isso acontecia, faltava, principalmente às universidades, o trabaTho de extensão com a comunidade, limitando assim os resultados esperados. $\mathrm{Na}$ outra ponta estavam as instituições privadas que, na compreensão de Bastos (1991a), só viam nesses cursos a possibilidade para expansão de suas atividades acadêmicas, face à interdição para abertura de novos cursos, imposta pelo Aviso Ministerial $n^{\circ} 1063 / 73$.

Em 30 de junho de 1978, foi editada a Lei $n^{\circ} 6.545$ (BRASIL, 1978), transformando as Escolas Técnicas Federais de Minas Gerais, do Paraná e Celso Suckow da Fonseca, do Rio de Janeiro, em Centros Federais de Educação Tecnológica - CEFET's, que têm por finalidade o oferecimento de educação tecnológica.

Segundo Bastos (1998), a criação dos CEFET's causou grande impacto no sistema de educação profissional do país, pois nesse sistema se encontra uma modalidade inovadora de formar jovens e reciclar profissionais, abrigando três níveis integrados de ensino, organizados vertical e horizontalmente: o técnico de $2^{\circ}$ grau, o tecnólogo e o engenheiro industrial, todos eles acompanhados da formação docente. 


\section{As mudanças causadas pela nova LDB na educação profissional}

Com a promulgação da nova LDB, Lei $n^{\circ} 9.394$ (BRASIL, 1996), a educação brasileira passa por mudanças significativas, entre elas a desvinculação do ensino médio do ensino técnico e, deixa claro em seu Capítulo II, seção IV, Art. 35, que o ensino médio é a etapa final da educação básica, com duração mínima de três anos.

O Decreto $n^{\circ} 2.208$ (BRASIL, 1997), ao regulamentar o $\S 2^{\circ}$ do art. 36 e os arts. 39 a 42 da referida lei indicou três níveis do ensino profissionalizante (art. $3^{\circ}$ ) e disciplinou a separação curricular entre o ensino médio (antigo segundo grau) e o nível técnico do ensino profissional (art. $5^{\circ}$ ).

Pesquisa realizada pelo Instituto Nacional de Pesquisas Educacionais Anísio Teixeira - INEP (2004) indica que o aumento do número de Centros de Educação Tecnológica foi de $75,5 \%$, passando de 53 para 93 instituições entre 2002 e 2003, segundo dados do Censo da Educação Superior de 2003. Apesar do crescimento registrado, os centros tecnológicos possuem apenas 1,6\% do total de alunos de graduação do país.

Outro dado mostrado em pesquisa realizada pelo INEP (2004), diz respeito ao crescimento dos cursos formadores de tecnólogos. Estes cresceram 64,7\% entre 2000 e 2002, mais que a totalidade dos cursos de graduação do Brasil e apresentaram aumento de 36\%. Em 2002, existiam no país
636 cursos de tecnologia, voltados à formação de tecnólogos para o mercado de trabalho. Estes cursos têm, normalmente, dois a três anos de duração. Do total de cursos, $66 \%$ são ofertados por instituições particulares.

Esse acelerado processo de expansão dos CST no país obriga o MEC a fazer uma reformulação na Educação Profissional; a mais recente é a edição dos Decretos $n^{\circ}$ 5.224 e n $^{\circ} 5.225$ (BRASIL, 2004) $)^{3}$. Todos os CEFET's, do ponto de vista jurídico, são alçados à condição das Universidades Públicas, ou seja, Instituições Federais de Educação Superior.

\section{Novo profissional para a sociedade}

Diante das novas linhas ditadas pelo atual governo, as Instituições de Ensino vêm há muito tempo discutindo qual a melhor maneira de formatar as grades curriculares dos cursos por elas oferecidos. Com a edição da LBD surgiu a necessidade de elaborar novas diretrizes curriculares nacionais. $\bigcirc$ que aconteceu com os cursos técnicos, cursos de tecnologia e com os cursos de engenharia?

Contudo, é necessário ter uma visão da realidade encontrada por esse profissional e sua inserção no mercado de trabalho. Tal preocupação já foi motivo de uma pesquisa realizada por Peterossi (1999), numa análise realizada em estudo apresentado, as principais características podem ser sintetizadas da seguinte forma:

I. Quanto à profissão do tecnólogo, os

3 Consta do Art. $11^{\circ}$ - Os Centros Federais de educação Tecnológica são instituições de ensino superior pluricurriculares, especializadas na oferta de educação tecnológica nos diferentes níveis e modalidades de ensino, caracterizando-se pela atuação na área tecnológica. 
dados apontam que os alunos estão preparados para exercer as atividades laborais correspondentes à sua formação superior. No entanto, a maioria ocupa cargos com denominação diferente ao título de seus diplomas.

II. A análise da trajetória profissional mostra que a maioria ingressou no mercado de trabalho ainda durante o seu curso. Ao término dele, a experiência profissional, o esforço próprio e a origem escolar permitem a inserção no primeiro emprego com facilidade.

Ao concluir a pesquisa, Peterossi (1999) sustenta o acompanhamento sistemático do aluno egresso como um dos instrumentos de fortalecimento institucional no cumprimento de seu papel social.

A responsabilidade de uma instituição de ensino é com a formação integral de seus discentes e não acaba quando estes concluem sua formação acadêmica. Cabe à instituição realizar pesquisas e buscar mecanismos de acompanhamento dos egressos com objetivos claros de melhorar sua formação acadêmica.

Para Peterossi (1999), a maior aproximação entre os Cursos de Tecnologia e o mercado de trabalho permite a profissionalização, a empregabilidade e o desempenho de variadas funções no campo da formação do aluno.

novo paradigma das grades curriculares caracteriza-se por aproximar as competências desejáveis para o desenvolvimento do indivíduo daquelas necessárias à sua inserção no processo produtivo. Portanto os educadores devem buscar desenvolver as competências básicas tanto para o exercício da cidadania como para o desempenho de atividades profissionais.
Cabe ressaltar que os responsáveis pelas informações ocupam cargos de liderança dentro das empresas e participam efetivamente dos planejamentos e decisões internas.

\section{Metodologia e procedimentos}

Em virtude dos objetivos estabelecidos, pode-se classificar esta pesquisa como exploratória. Para Gil (1999), as pesquisas exploratórias têm como principal finalidade desenvolver, esclarecer e modificar conceitos e idéias, tendo em vista, a formulação de problemas mais precisos ou hipóteses pesquisáveis para estudos posteriores.

Neste enfoque e considerando-se que a revisão da literatura realizada auxiliou na compreensão histórica dos CST e sua trajetória pela educação profissional do país, bem como a implantação desses cursos no CEFET-PR, decidiu-se ir a campo com o objetivo de entender a dimensão da compreensão e aceitação que as empresas têm sobre o novo profissional formado nos referidos cursos.

Como a abordagem desta pesquisa qualitativa, Oliveira (2001), vale observar que o tratamento qualitativo dado a uma pesquisa é adequado para entender a relação de causa e efeito do fenômeno e, conseqüentemente, chegar à sua verdade e razão.

A coleta de dados foi iniciada com a aplicação de um questionário que permitiu levantar informações quantitativas acerca de diversas questões, tais como o número de profissionais formados nos cursos técnicos, de tecnologia e engenharia que atuam nas empresas, as necessidades da empresa por esses profissionais; o enquadra- 
mento deles no plano de cargos e salários da empresa, além de investigar se há estagiários dos CST nas empresas e se têm intenção na contratação desse estagiário.

A seleção das empresas foi realizada a partir de informações existentes no CEFET-PR, através de sua Gerência de Relações Empresarias - GEREC, que utilizou um cadastro e-mail de 60 empresas de sua mala direta. Do total de questionários enviados obteve-se o retorno de 32 empresas, o que representa um total de $53,33 \%$ de respostas.

Num segundo momento da coleta de dados, foram realizadas entrevistas nas empresas escolhidas. $O$ critério adotado para a composição da amostragem foi o da seleção das empresas que apresentavam maior número de tecnólogos trabalhando. $O$ estudo foi delimitado às empresas de médio e grande porte. Entre as empresas pesquisadas optou-se para a realização da entrevista em três empresas de médio porte e três de grande porte.

Para definição dos entrevistados deu-se preferência por pessoas que pudessem contribuir com os questionamentos da pesquisa. Definiu-se então por entrevistar no Bloco I - Necessidade da empresa por profissionais formados nos CST, uma pessoa da área de Recursos Humanos. E no Bloco II Atuação do profissional formado nos CST, uma pessoa de liderança das áreas de produção na empresa. Após a confirmação do colaborador por e-mail, programou-se a visita para efetuar a entrevista. Para efeito de apresentação dos resultados, os entrevistados foram codificados com números que vão de 01 até 12.
A pesquisa é um estudo de caso. Para Yin (2001), o estudo de caso contribui, de forma inigualável, para a compreensão que se tem dos fenômenos individuais, organizacionais, sociais e políticos.

$\mathrm{Na}$ análise do material empírico foi seguido o caminho proposto por Gomes, que aponta algumas considerações iniciais a serem verificadas na fase de análise. Segundo Gomes (1999), cabe ao pesquisador:

1. estabelecer uma compreensão dos dados levantados;

2. confirmar ou não os pressupostos da pesquisa;

3. responder às questões formuladas e ampliar o conhecimento sobre o assunto, articulando-o ao contexto cultural do qual faz parte.

Para atender aos objetivos propostos na pesquisa e possibilitar uma melhor compreensão dos conteúdos das entrevistas, surgiram três categorias dos dados levantados pelos entrevistados: a) necessidade das empresas por tecnólogos; b) o perfil profissional do tecnólogo e sua atuação na empresa, e c) o tecnólogo, o técnico e o engenheiro, no organograma empresarial.

\section{Análise do questionário de pesquisa}

questionário aplicado procurou determinar a classificação econômica das empresas. Para isso foi utilizado o parâmetro do Instituto Brasileiro de Geografia e Estatística - IBGE, ano de 2005, apresentando a seguinte classificação: $50 \%$ de micro e pequenas empresas, $29 \%$ de empresas de porte médio e $21 \%$ de grandes empresas. 


\section{Necessidade das empresas por empregados formados nos cursos}

$\mathrm{Na}$ pesquisa ficou evidente a grande necessidade das empresas pesquisadas por profissionais formados nos cursos técnicos. Entre essas empresas a grande maioria assinalou como muito grande e grande a necessidade desse profissional.

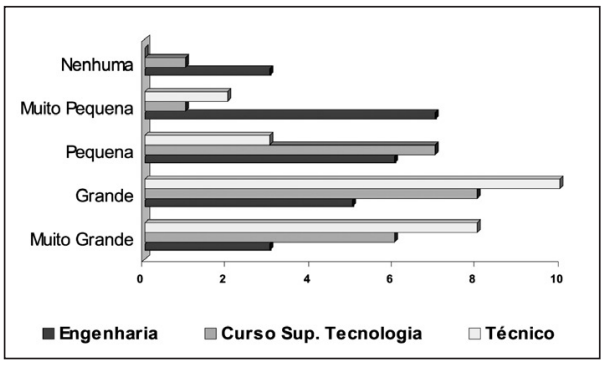

Gráfico 1 - Necessidade das empresas por profissionais formados nos cursos.

Fonte: dados trabalhados pelo autor (2006).

\section{Cargo exercido nas empresas pelos profissionais formados nos cursos}

Procurou-se evidenciar o nível ocupacional que o técnico, tecnólogo e engenheiro ocupam nas empresas pesquisadas. É importante salientar que nas respostas apresentadas poderia ser assinalado mais de um nível ocupacional.

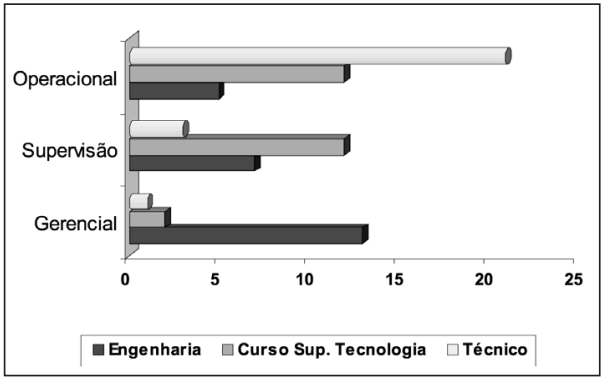

Gráfico 2 - Cargo exercido nas empresas pelos profissionais formados nos cursos.

Fonte: dados trabalhados pelo autor (2006).

\section{Faixa salarial do profissional dentro das empresas (em salários mínimos)}

Os resultados apresentados pontuam a questão salarial dos empregados formados nos cursos técnicos, CST e de engenharia que atuam dentro das empresas pesquisadas. É importante postular que das 32 empresas pesquisadas 12 não apresentaram os salários pagos aos profissionais tecnólogos, constatando-se que em algumas não há o profissional trabalhando e outras optaram em não fornecer essa informação. $\bigcirc$ mesmo se repetindo em 11 empresas no caso dos engenheiros e sete empresas com os profissionais de nível técnico.

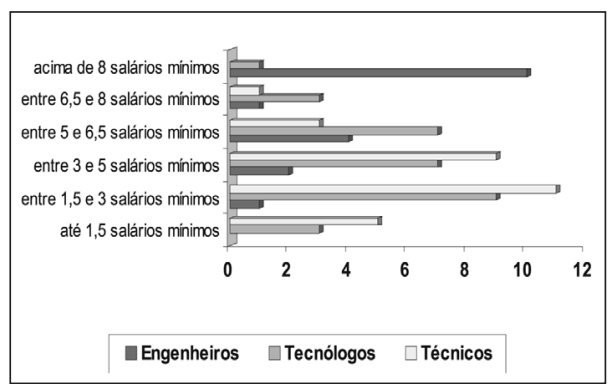

Gráfico 3 - Faixa salarial do profissional nas empresas em salário mínimo.

Fonte: dados trabalhados pelo autor (2006).

\section{Interesse das empresas na efetivação dos estagiários}

$\mathrm{Na}$ pesquisa foi verificado se existe nas empresas o estagiário dos CST, e também, se há por parte da empresa interesse na contratação destes. A manifestação de interesse ou não de efetivar o estagiário como colaboradores no futuro, pode-se observar que existe em $68 \%$ das empresas pesquisadas o estagiário dos CST e 78\% destas empresas pretendem efetivar esse estagiário e $22 \%$ não pretendem. 


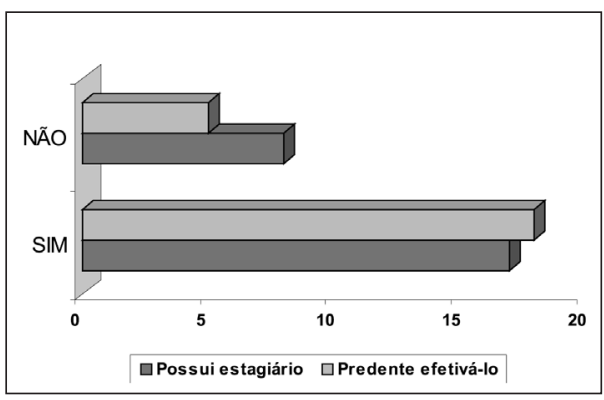

Gráfico 4 - Interesse das empresas na efetivação de estagiários dos CST.

Fonte: dados trabalhados pelo autor (2006).

\section{Interpretação das entrevistas Necessidade de tecnólogos pelas empresas}

Nesta categoria enfoca-se a opinião dos entrevistados quanto às necessidades das empresas por profissionais tecnólogos. Num primeiro momento observa-se que não há distinção na forma de contratação destes profissionais em comparação com os demais. $O$ processo de seleção utilizado é o mesmo. Apenas um fato foi destacado pela entrevistada 12 que faz a seguinte afirmação: "com o tecnólogo, não temos a avaliação prática. Olhamos muito mais o lado do potencial dele, e da experiência que ele pode trazer para a empresa".

A qualificação do tecnólogo tornase um ponto comum às empresas que contratam esse tipo de profissional. Exemplificado pela entrevistada 10, "a questão de contratação do tecnólogo para nós, acredito que veio assim como uma opção da empresa em ter profissional mais qualificado, com um conjunto teórico, num nível melhor do que se encontra atualmente".
As empresas necessitam de uma aprendizagem contínua, pois o ambiente tecnológico mundial evolui muito rapidamente. Essa evolução leva, muitas vezes, as empresas a mudarem seus paradigmas. Esta realidade é citada pelo entrevistado 01 :

Os equipamentos que tínhamos no início da fábrica eram operados basicamente por pessoas muito simples, de formação escolar quase nenhuma. Mas os equipamentos de hoje são bastante sofisticados, bastante sensíveis, e não é qualquer pessoa que pode operar. Por isto estamos buscando através de profissionais mais qualificados, começando pelos técnicos, que num primeiro momento trabalhavam só com manutenção, e hoje atuam em varias áreas, como manutenção, projetos planejamento e controle.

Outro ponto levantado pela pesquisa refere-se à continuidade da utilização do tecnólogo como força de trabalho dentro da empresa. Para dois entrevistados, mesmo havendo o interesse na continuidade de contratação destes profissionais, existe um fator limitador. No entendimento do entrevistado 01, "pelo sucesso que temos obtido com os profissionais que vieram para a empresa, a tendência é que haja continuidade, lógico temos uma certa limitação na absorção destes profissionais, mas a tendência é realmente buscar profissionais cada vez mais capacitados, eu acho que até fazendo uma substituição de quantidade por qualidade".

Observou-se também que apesar de existirem desde o início dos anos 70, os CST são pouco conhecidos na região pesquisada. Só com a edição da atual LDB é que algumas instituições de ensino passaram a ofertar esta modalidade dentro da educação profissional na região. 
Esta questão ficou evidente na fala do entrevistado 06, "este termo tecnólogo é um pouco novo, para mim pessoalmente, porque eu não convivi muito tempo com isso, o normal da gente conhecer em outras empresas é o técnico e o engenheiro".

Para algumas empresas ainda existe certa dificuldade em contratar esse tipo de profissional, como pontua a entrevistada 12:

Temos dificuldades, primeiro que não existe uma oferta grande destes cursos, segundo que temos dificuldade de trazer este profissional para a empresa. Eu não sei como eles direcionam a sua carreira. Não temos um conforto para se dizer que se tem esta mão de obra, que é fácil de contratar, porque é muito difícil. Com esta formação para os cargos que existem na empresa, é difícil conseguir fazer uma dinâmica de grupo.

Os CST têm se apresentado para a nação brasileira como uma alternativa dentro da educação superior. A formação mais rápida e específica voltada à necessidade do setor produtivo, pode levar a um falso diferencial sobre os cursos de formação generalista.

Na visão de Teixeira (2004), vive-se numa época de escasso ou nenhum crescimento econômico e do desemprego em massa, e a tendência é responsabilizar a educação por isso. Relacionar educação com empregabilidade é atribuir à primeira, e principalmente ao próprio trabalhador essa responsabilidade.

Na questão específica dos tecnólogos se faz necessário um trabalho de divulgação deste profissional frente ao setor produtivo, que deve ser realizado pelas instituições formadoras e pelos próprios egressos destes cursos.

\section{O perfil profissional do tecnólogo e sua atuação dentro da empresa}

Um dos tópicos da pesquisa é verificar a atuação do tecnólogo no setor produtivo. Inicialmente, procurou-se detectar junto aos entrevistados se o perfil deste profissional está atendendo às necessidades da empresa. Constatou-se que para todos os entrevistados o perfil do profissional tecnólogo atende de certa forma às necessidades de suas empresas. Porém, algumas observações foram levantadas e merecem reflexão.

De acordo com Bastos (1998), o profissional tecnólogo desenvolve suas atividades no âmbito da execução das tecnologias e, deve estar apto a aplicar métodos e conhecimentos tecnológicos, acima do nível de simples atividades técnicas. Pode-se verificar esta atuação na fala do entrevistado 04:

Nós temos uma equipe nova, quer dizer em renovação, a equipe mais antiga está na área produtiva, antigos caldeireiros, antigos soldadores. A parte pensante é a parte que lidera as equipes da empresa, é novo e notório o reconhecimento desta nova equipe pelas auditorias externas que a gente sofre. Os auditores falam que é interessante os influenciadores da empresa ou quem coordena os trabalhos em relação a gestão integrada. Todo auditor fala isto, é difícil encontrar em uma empresa tanta gente nova numa sala de reuniões, isto é decorrente da maioria serem formados na área tecnológica.

Uma questão já abordada no trabalho, sobre a necessidade muito grande da região por profissionais formados em cursos técnicos de nível médio, aparece de forma mais acentuada nas palavras do entrevistado 10, "nós aqui pegamos os tecnólogos 
que contratamos para fazer serviço de técnico, pois temos uma deficiência muito grande por técnicos com o nível de capacitação que tem um tecnólogo do CEFET-PR".

Outro ponto interessante no cenário atual, sobre os CST serem cursos de graduação, não ficou tão clarificado para o entrevistado 10 que entende "o perfil em que se está formando o tecnólogo, ainda tem uma extrema confusão do próprio profissional, porque ele não é um profissional de terceiro grau formado, ele tem condições de fazer um mestrado. Nem é um técnico".

Entendimento um pouco diferente do apresentado pelo entrevistado 01, "não usamos o tecnólogo para operar equipamentos, temos o tecnólogo fazendo um trabalho de sustentação, um trabalho de acompanhamento, um trabalho de análise, porque pela formação dele, auxilia a própria engenharia na questão de obtenção da melhor performance".

Buscou-se, ainda, discutir na pesquisa em que espaço vem atuando o tecnólogo e qual seria a ocupação ideal deste profissional nas empresas.

$\mathrm{Na}$ análise das respostas dos entrevistados deve-se ter em mente as diversidades de cultura em que as empresas estão inseridas, como: características, mercado, forma de trabalho. Mas isto mostra também a empregabilidade deste profissional e sua diversidade de atuação na ocupação real, que passa por área de qualidade, manutenção preventiva, líder de equipe, coordenação de trabalhos, ainda desempenha atividades na área de produção e elabora projetos em cima de padrões definidos.
Na ocupação ideal pode-se destacar a questão de desenvolvimento de pesquisa, gestão autônoma de resultados, planejamento de áreas específicas, área de projetos. Modificações de equipamentos que vêm ao encontro da formação recebida por estes profissionais.

\section{O tecnólogo, o técnico e o engenheiro no organograma das empresas pesquisadas}

A última categoria a ser analisada na pesquisa refere-se à convivência entre o tecnólogo, o técnico e o engenheiro no cenário produtivo. Na aplicação do questionário enviado às empresas, procurou-se levantar qual o nível ocupacional em que estes profissionais atuam. Na análise das respostas, fica bem definido que os cargos de gerentes são ocupados em sua maioria por engenheiros; os cargos em nível operacional são ocupados pelos técnicos, ficando os tecnólogos com atuação em cargos de nível de supenvisão e operacional.

Mais uma vez surge alguma dificuldade por parte das empresas em inserir os tecnólogos no quadro de cargos e salários. Mas, qual o papel que este profissional vem desempenhando no setor produtivo? Quais as suas carências frente ao mercado? Buscou-se na pesquisa questionar a percepção dos agentes que atuam neste setor sobre os questionamentos levantados.

Dois entrevistados relatam que falta ao tecnólogo experiência prática, voltada principalmente aos processos produtivos. Apenas uma empresa não vê carências neste tipo de profissional, porém ressalta a falta de formação em mineração de subsolo, área de atuação dela. Os demais colocam questões de ordem generalista como: gestão de pessoas, motivação pessoal, visão global dos processos industriais. 
Na visão do entrevistado 04 em cuja empresa a maioria dos tecnólogos contratados já eram funcionários:

Eu percebo um pouco de carência na parte de gestão de pessoas. Você o coloca para liderar, ele lidera solução de serviços, cumprimento de prazos, parte técnica, na parte de gerir pessoas eles têm um pouco de dificuldade. Outra carência que eu percebo própria de todo técnico, tecnólogo, e engenheiro é a dificuldade de relacionamento fora. Hoje em dia as informações não estão dentro da empresa, estão fora. Então você percebe que demora um pouco para o pessoal ter contato com os clientes.

Quanto ao papel que o tecnólogo desempenha no setor produtivo e seu relacionamento com outros profissionais, o entrevistado 11 afirma: "eu penso que o tecnólogo é um profissional atualizado, isto não é problema, consegue ter uma boa criatividade, consegue ter a visão do processo. Faltathe uma visão um pouco mais prática de determinados processos de produção".

Sobre a atuação do tecnólogo, do técnico e do engenheiro o entrevistado 11 apresenta a seguinte visão:

Olha, eu acredito que a empresa hoje está começando a definir como vão ser os tecnólogos. Como vão ser os engenheiros dentro da empresa. Hoje nós temos cargos de liderança dentro da empresa que são dos tecnólogos. Então está bem dividido. Eu acho que os dois têm espaço. Vai realmente daquilo que ele tem para apresentar e qual a área de atuação que vai ser definida. Mas eu acredito que, hoje, entre tecnólogo e engenheiro não exista diferença. Temos supervisão em ambas as formações. Técnicos que hoje eu não vejo.
De acordo com o entrevistado 02 não há sombreamento do tecnólogo sobre o engenheiro. Salienta ainda, "que tenho percebido é cada vez mais a evolução dos técnicos e tecnólogos. A capacidade que os tecnólogos têm demonstrado em resolver questões, antes restritas aos engenheiros, sempre respeitando as classes de cada um, mas a gente percebe um amadurecimento da classe neste ponto".

Cabe aqui novamente lembrar o ConseIheiro Cordão no Parecer CNE/CP n ${ }^{\circ} 29$ (BRASIL, 2002), em cujo relato evidencia que embora o tecnólogo esteja situado na fronteira de atuação do técnico e do bacharel, deve ter uma identidade própria e específica em cada área de atividade econômica.

\section{Considerações finais}

Fazendo-se uma leitura do cenário da região pesquisada, o resultado mostra que $58 \%$ da força de trabalho é composta por técnicos e a necessidade dela por este profissional é muito grande. Quanto aos tecnólogos, comparando-os aos demais profissionais, observa-se que não há distinção na forma de contratá-los.

A necessidade por profissionais com formação técnica faz com que algumas empresas subutilizem a força de trabaIho dos tecnólogos. Porém, a necessidade por profissionais mais qualificados é unânime nas empresas, sendo este um dos motivos que as levam a contratar 0 profissional tecnólogo. E entre os profissionais tecnólogos e engenheiros vale ressaltar que na soma dos itens de necessidade grande e muito grande, $64 \%$ das empresas manifestaram a preferência aos tecnólogos. 
Todas as empresas pesquisadas explicitaram que a continuidade na contratação de tecnólogos é um ponto positivo para elas, pois significa qualificar os colaboradores. Existe um fator limitador uma vez que o quadro de colaboradores é limitado, principalmente nas empresas de porte médio, o que mostra uma preocupação na oferta contínua de tecnólogos em uma só área de formação.

A análise da ocupação de cargos traz claramente uma definição para a categoria funcional dos engenheiros em nível de gerenciamento nas empresas: os profissionais formados nos cursos técnicos ocupam cargos de nível operacional, enquanto os tecnólogos atuam em nível de supervisão e operacional. Constata-se novamente a indefinição sobre este profissional.

Comparando-se os salários recebidos, nota-se o favorecimento aos engenheiros. Segundo os dados, os engenheiros ficam com média salarial acima dos oito salários mínimos; os técnicos mantêm uma média salarial entre um e meio a cinco salários mínimos. Já entre os tecnólogos não há ainda uma faixa salarial definida, mas $47 \%$ deles recebem entre três a seis e meio salários mínimos.

Pode-se ressaltar que mesmo não havendo uma definição nas empresas pesquisadas, na ocupação de cargos, como nos salários pagos aos profissionais formados nos CST, as dificuldades no reconhecimento desse profissional são de alguma forma justificadas, tanto pelo tempo de existência desses cursos quanto pelos poucos profissionais que atuam no mercado de trabatho. Ainda assim 68\% destas empresas possuem estagiários desses cursos e 79\% delas pretendem efetivá-los. perfil do profissional tecnólogo atende às necessidades das empresas, pois o mesmo tem atuado e colaborado no desenvolvimento de novas tecnologias nas áreas de qualidade, manutenção preventiva, líder de equipe, coordenação de trabaIho, mostrando que existe espaço para este profissional nas empresas pesquisadas.

A falta de experiência prática é uma das carências levantadas sobre o profissional tecnólogo. As demais são também atribuídas a outros profissionais dentro da educação tecnológica: como gestão de pessoas; motivação pessoal e envolvimento com o processo global da empresa.

Não há no ambiente das empresas dificuldade de relacionamento entre técnicos, tecnólogos e engenheiros. Um dado levantado na pesquisa foi o sombreamento dos tecnólogos sobre os engenheiros, o que não ocorre dentro do ambiente da empresa. Outra questão levantada foi sobre o reconhecimento deste profissional pelos reguladores de classe.

A hipótese levantada no início da pesquisa pode ser sustentada após a análise do questionário enviado às empresas e as entrevistas realizadas. Os resultados mostram que há, por parte das empresas, a necessidade por profissionais formados nos CST. Na maioria dos casos, o profissional formado nos CST atua dentro de sua área de formação e sua convivência com outros profissionais formados nas áreas tecnológicas dá-se normalmente.

Ainda existe certa dificuldade por parte das empresas em entenderem o papel deste novo profissional frente aos desafios tecnológicos, o que pode acarretar prejuízo, tan- 
to por parte da empresa, por não empregar este profissional de maneira correta, como por parte do profissional que se vê obrigado a assumir cargos em níveis inferiores àqueles em que poderia estar atuando.

Cabe então às instituições formadoras destes profissionais um trabalho de conscientização da sociedade em geral sobre as competências e habilidades adquiridas por eles durante a sua formação e como utilizá-las de maneira a satisfazer, tanto ao profissional como à sociedade.

A aproximação com o ambiente produtivo deve ser um dos objetivos das instituições de ensino que atuam na educação profissional. Não há como estabelecer uma relação direta com o trabaTho utilizando para formação profissional apenas os ambientes de sala de aula e laboratórios existentes. Também cabe à empresa entender os mecanismos internos destas instituições formadoras de profissionais tão necessários ao desenvolvimento da sociedade.

$\mathrm{Na}$ complexidade das questões abordadas na presente pesquisa, fruto de questionamentos históricos e da vivência de muitos profissionais que atuam no âmbito do ensino profissionalizante e nas empre- sas do país, destaca-se a pouca literatura e pesquisa na área.

Assim propõe-se o permanente diálogo entre a pesquisa e os cenários complementares sugeridos abaixo:

a. pesquisar junto aos alunos egressos dos CST, sua atuação no do setor produtivo formal e também como profissional liberal;

b. ampliar as pesquisas para outras regiões, buscando determinar o campo de atuação do tecnólogo nas diferentes áreas de formação;

c. pesquisar junto aos conselhos de classe e associação dos profissionais quais os melhores procedimentos a serem adotados para definir o papel a ser desempenhado pelo profissional tecnólogo;

O tecnólogo no ambiente produtivo há de ser instado a colaborar em várias frentes, principalmente em face às novas tendências tecnológicas, uma vez que ele recebe conhecimento teórico e prático e pode contribuir eficazmente tanto com as empresas quanto com a sociedade. Basta para isso que se promovam interações entre lideranças empresarias, governamentais, da academia e de outras organizações sociais comprometidas com o desenvolvimento industrial e tecnológico. 


\section{Referências}

ACIOLI, M. F. C. L. Cursos tecnológicos: emergência de uma nova regulamentação. In: CONGRESSO LUSO-AFRO-BRASILEIRO DE CIÊNCIAS SOCIAIS, 8., 2004, Coimbra. Actas... Coimbra: Centro de Estudos Sociais, 2004.

ALMEIDA JUNIOR, E. P. Empregabilidade do profissional formado nos Cursos Superiores de Tecnologia do CEFET-PR: o caso das médias e grandes empresas da Região Norte do Paraná. 2005. 138 f. Dissertação (Mestrado em Engenharia de Produção)-Programa de Pós-Graduação em Engenharia de Produção, Centro Federal de Educação Tecnológica do Paraná, Ponta Grossa, 2005.

BASTOS, J. A. S. A. Cursos superiores de tecnologia: avaliação e perspectivas de um modelo de educação técnico profissional. Brasília: SENETE, 1991a.

A educação técnico-profissional: formação profissional e impacto tecnológico.

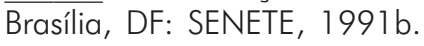

- Tecnologia \& interação: a educação tecnológica: conceitos, características e perspectivas. Curitiba: CEFET-PR, 1998.

BRASIL. Decreto $n^{\circ} 5.224$, de $1^{\circ}$ de outubro de 2004. Dispõe sobre a organização dos Centros Federais de Educação Tecnológica e dá outras providências. Diário Oficial [da] República Federativa do Brasil, Brasília, DF, 1 out. 2004.

Disponível em: <http://portal.mec.gov.br/setec/arquivos/pdf/Decreto_5.224.pdf>. Acesso em: 16 fev. 2006.

BRASIL. Decreto ${ }^{\circ} 5.225$, de $1^{\circ}$ de outubro de 2004. Altera dispositivos do Decreto $n^{\circ}$ 3.860, de 9 de julho de 2001, que dispõe sobre a organização do ensino superior e a avaliação de cursos e instituições, e dá outras providências. Diário Oficial [da] República Federativa do Brasil, Brasília, DF, 1 out. 2004.

Disponível em: <http://www.presidencia.gov.br/CCIVIL/Ato2004-2006/2004/Decreto/ D5225.htm>. Acesso em: 16 fev. 2006.

BRASIL. Lei n. 4.024, de 20 de dezembro de 1961. Fixa as diretrizes e bases da educação nacional. Diário Oficial [da] República Federativa do Brasil, Brasília, DF, 27 dez. 1961. P. 11.429. Disponível em: www.planalto.gov.br/ccivil_03/Leis/L4024.htm. Acesso em: 9 ago. 2007.

BRASIL. Lei $n^{\circ}$. 5.540, de 28 de novembro de 1968. Fixa normas de organização e funcionamento de ensino superior e sua articulação com a escola média, e dá outras providências. Diário Oficial [da] República Federativa do Brasil, Brasília, DF, 29 out. 1968. Disponível em: <www6.senado.gov.Br>. Acesso em: 8 ago. 2007. 
BRASIL. Lei n 6.545, de 4 de junho de 1978. Dispõe sobre a transformação das Escolas Técnicas Federais de Minas Gerais, do Paraná e Celso Suckow da Fonseca em Centros Federais de Educação Tecnológica e dá outras providências. Lex: legislação básica do Centro Federal de Educação Tecnológica do Paraná, Curitiba, 1999.

BRASIL. Lei n 9.394, de 20 de dezembro de 1996. Estabelece as diretrizes e bases da educação nacional. Diário Oficial [da] República Federativa do Brasil, Brasília, DF, 23 dez. 1996.

BRASIL. Ministério da Educação. Decreto n².208, de 17 de abril de 1997. Regulamenta o $\S 2^{\circ}$ do art.36 e os arts. 39 a 42 da Lei $n^{\circ} 9.394$, de 20 de dezembro de 1996, que estabelece as diretrizes e bases da educação nacional. Diário Oficial [da] República Federativa do Brasil, Brasília, DF, 17 abr. 1997.

BRASIL. Ministério da Educação. Secretaria da Educação Média e Tecnológica. Educação profissional: legislação básica. Brasília, RJ, 2001.

Disponível em: <http://www.conexaodanca.art.br/imagens/caminho/LegisBasica.pdf>. Acesso em: 16 fev. 2006.

BRASIL. Tribunal de Contas da União. Secretaria Geral de Controle Externo. Auditoria no Programa de Educação Profissional: Acórdão 480/2005. Plenário: relatório final e anexos. Brasília, DF, 2005b.

BRASIL. Tribunal de Contas da União. Secretaria de Controle Externo do Estado do Paraná. Relatório de execução de auditoria de natureza operacional: TC n 015.672/2002-5: período de execução: 24/05/2004 a 14/06/2004. Curitiba, 2005.

CONSELHO FEDERAL DE EDUCAÇÃO (Brasil). Parecer $n^{\circ} .45$, de 12 de janeiro de 1971. A qualificação para o trabalho no ensino de $2^{\circ}$ grau. Brasília, DF, 1972.

CONSELHO NACIONAL DE EDUCAÇÃO (Brasil). Câmara de Educação Básica. Parecer CNE/CEB n 14, de 5 de maio de 2004. Autoriza as escolas agrotécnicas federais a ofertarem cursos superiores de tecnologia, em caráter experimental. Portal SETEC, Brasília, DF, 2006. Disponível em: <http://portal.mec.gov.br/setec/arquivos/pdf/ legisla05.pdf>. Acesso em: 16 fev. 2006.

CONSElHO NACIONAL DE EDUCAÇÃO (Brasil). Conselho Pleno. Parecer CNE/CP n 29/2002, de 12 de dezembro de 2002. Trata das diretrizes Curriculares Nacionais no nível Tecnológo. Diário Oficial [da] República Federativa do Brasil, Brasília, DF, 13 dez. 2002. Disponível em: <http://portal.mec.gov.br/setec/arquivos/pdf/legisla05.pdf>. Acesso em: 16 fev. 2006. 
GIL, A. C. Métodos e técnicas de pesquisa social. 5. ed. São Paulo: Atlas, 1999.

GOMES, R. Análise de dados em pesquisa qualitativa. In: MINAYO, M. C. S. (Org.). Pesquisa social: teoria, método e criatividade. 14. ed. Petrópolis: Vozes, 1999.

CURSOS tecnológicos lideram crescimento na graduação. Informativo INEP, Brasília, DF, 17 fev. 2004. Disponível em: <http://www.inep.gov.br/informativo/informativo27.htm> Acesso em: 16 fev. 2004.

HISTÓRIA da educação no Brasil: período do Estado Novo (1937 a 1945). Rio de Janeiro, [1998?]. Disponível em: <http://www.pedagogiaemfoco.pro.br/heb08.htm> Acesso em: 30 out. 2004.

KUENZER, A. Z. Ensino médio e profissional: as políticas do Estado neoliberal. São Paulo: Cortez, 1997.

LAUDARES, J. B.; TOMASI, A. O técnico de escolaridade média no setor produtivo: seu novo lugar e suas competências. Educação \& Sociedade, Campinas, v. 24, n. 85, 2003. Disponível em: < http://www.scielo.br/scielo.php? script=sci arttext\&pid=S0101$73302003000400007 \& \operatorname{lng}=$ pt\&nrm $=$ iso >. Acesso em: 16 fev. $200 \overline{6}$.

LINSINGEN, I. V.; BAZZO, W. A. Novos modelos de produção e a formação do engenheiro: uma abordagem CTS. NEPET, Florianópolis, 2000. Disponível em: <http:// www.emc.ufsc.br/ nepet/Artigos/Texto/Mod_Prod.htm> Acesso em: 16 fev. 2006.

NOTÍCIAS SETEC. Brasília, DF: MEC, Secretaria de Educação Profissional e Tecnológica, n. 64, p. 11-17, out. 2004. Disponível em: <http://www.mec.gov.br/news/ boletim_semtec.asp?edicao=36>. Acesso em: 16 fev. 2006.

OLIVEIRA, S. L. Tratado de metodologia científica: projetos de pesquisas, TGI, TCC, monografias, dissertações e teses. São Paulo: Pioneira, 2001.

PETEROSSI, H. G. Educação e mercado de trabalho: análise crítica dos cursos superiores de tecnologia. São Paulo: Edições Loyola, 1980.

- O tecnólogo e o mercado de trabalho: acompanhamento dos alunos egressos da Fatec-SP. São Paulo: FAT, 1999.

ROMANO, C. A. O desafio de uma nova proposta para a graduação na educação profissional: o caso do CEFET-PR. 2000. 153 f. Dissertação (Mestrado em Engenharia de Produção)-Programa de Pós-Graduação em Engenharia de Produção, Universidade Federal de Santa Catarina, Florianópolis, 2000. 
TEIXEIRA, D. C. L. Cursos tecnológicos e a questão da empregabilidade. Revista Educação e Trabalho, Maceió, n. 1, 2004.

VITORETTE, J. M. B. A implantação dos cursos superiores de tecnologia no CEFET-PR. 2001. 133 f. Dissertação (Mestrado em Tecnologia)-Programa de Pós-Graduação em Tecnologia, Centro Federal de Educação Tecnológica do Paraná, Curitiba, 2001.

YIN, R. K. Estudo de caso: planejamento e métodos. 2. ed. Porto Alegre: Bookman, 2001.

Recebido em: 20/02/2007

Aceito para publicação em: 05/06/2007 